\title{
Facile and Rapid Synthesis of Durable SSZ-13 Catalyst Using Choline Chloride Template for Methanol-to-Olefins Reaction
}

\author{
Xiongchao Lin ${ }^{1}$, Sasha Yang ${ }^{1,2, *}$, Xiaojia Li ${ }^{1}$, Caihong Wang ${ }^{1}$ and Yonggang Wang ${ }^{1}$ \\ 1 School of Chemical \& Environmental Engineering, China University of Mining and Technology (Beijing), \\ D11 Xueyuan Road, Haidian District, Beijing 100083, China; 1xc@cumtb.edu.cn (X.L.); \\ 1xj1209894599@163.com (X.L.); wangcaihong2005@126.com (C.W.); wangyg@cumtb.edu.cn (Y.W.) \\ 2 Department of Chemical and Biological Engineering, Monash University, Wellington Road, \\ Clayton, VIC 3800, Australia \\ * Correspondence: sashayang2009@gmail.com; Tel.: +86-10-6233-9882
}

Citation: Lin, X.; Yang, S.; Li, X.; Wang, C.; Wang, Y. Facile and Rapid Synthesis of Durable SSZ-13 Catalyst Using Choline Chloride Template for Methanol-to-Olefins Reaction. Catalysts 2021, 11, 1250. https:// doi.org/10.3390/catal11101250

Academic Editor:

Enrique García-Bordejé

Received: 28 September 2021

Accepted: 13 October 2021

Published: 18 October 2021

Publisher's Note: MDPI stays neutral with regard to jurisdictional claims in published maps and institutional affiliations.

Copyright: (c) 2021 by the authors. Licensee MDPI, Basel, Switzerland. This article is an open access article distributed under the terms and conditions of the Creative Commons Attribution (CC BY) license (https:// creativecommons.org/licenses/by/ $4.0 /)$.

\begin{abstract}
In the current study, a facile and rapid synthesis approach for a SSZ-13 catalyst using choline chloride (CC) as a template was proposed, and the catalytic performance for the methanol-to-olefins (MTO) reaction was examined. With a proper amount of $\mathrm{CC}$ addition (i.e., $\mathrm{m}(\mathrm{CC}) / \mathrm{m}\left(\mathrm{SiO}_{2}\right)=0.14$ ), uniform and homogeneously distributed cubic SSZ-13 crystals were obtained within $4 \mathrm{~h}$ with lower aggregation. The synthesized catalyst demonstrated excellent porous features with a total specific surface area and mesopore volume of $641.71 \mathrm{~m}^{2} \cdot \mathrm{g}^{-1}$ and $0.04 \mathrm{~cm}^{3} \cdot \mathrm{g}^{-1}$, respectively. The optimized strong and weak acid sites on SSZ-13 were obtained by regulating the $\mathrm{m}(\mathrm{CC}) / \mathrm{m}\left(\mathrm{SiO}_{2}\right)$ ratio. The less strong acid sites and a larger amount of weak acid sites in the synthesized catalyst were conducive to the catalytic performance of the MTO reaction under a lower reaction temperature $\left(450{ }^{\circ} \mathrm{C}\right)$. The appropriate acidity and well-developed pore structure of synthesized SSZ-13 could also slow down the carbon deposition rate and, thus, significantly improve the catalytic lifetime of the catalyst. The methanol conversion rate and initial selectivity of light olefin using the synthesized catalyst could maintain over $95 \%$ and $50 \%$, respectively, and a lifetime of $172 \mathrm{~min}$ was achieved. Although the low olefin selectivity of the synthesized SSZ-13 catalyst was slightly lower than that of the purchased one, its desirable features were thought to have good potential for industrial application.
\end{abstract}

Keywords: SSZ-13; MTO; choline chloride template; catalyst

\section{Introduction}

The methanol-to-olefins (MTO) reaction has been intensively studied in recent years with a particular focus on the development of highly reactive and durable catalysts [1-3]. Chabazite (CHA) zeolite with a favorable structure is expected to be an ideal candidate for the MTO reaction [4,5]. As a promising CHA material, SSZ-13 has a unique porous structure and a high hydrothermal stability that enables its high efficiency and selectivity [6,7]. The ordered crystal structure is quite essential for the preparation of the SSZ-13 zeolite. Conventionally, the costly N, N, N-trimethyl-1-adamantyl ammonium hydroxide (TMADaOH) was used as a template for the synthesis of SSZ-13. Although the properties of the hierarchical pore SSZ-13 are excellent, its synthesis process is complicated with the inevitable environmental pollution caused by the toxic template precursor TMADaOH. In addition, a long synthesis period (more than one week) is usually needed to compensate for the slow growth of the crystal. Therefore, the development of an environmentally friendly and cost-effective template agent or non-template agent method with a reduced synthesis cycle remains a challenge to be tackled. A novel route for rapid and facile synthesis of the SSZ-13 catalyst is crucial and necessary.

The key factors affecting the synthesis of the SSZ-13 zeolite are the template and processing conditions. The seed-guided method complying with the core-shell growth mechanism in the crystallization process could affect the structure of the molecular sieve. 
Synthesis of a high-purity SSZ-13 molecular sieve was achieved by crystallization under $100{ }^{\circ} \mathrm{C}$ for 4 days after exploring the influence of the number of seeds [8,9]. Alternatively, the synthesis period of the SSZ-13 zeolite was significantly decreased to a few hours by steam-assisted crystallization without the aid of a seed crystal [10,11]. Currently, an emerging process of a template method for controlling the mesoporous structure and adjusting the size of the pore channel is now attracting more attention. A series of growthmodifier-assisted synthesis methods were established based on the disclosed particle attachment crystallization mechanism. Particularly, significant progress has been made in the use of polymers to control the synthesis of zeolites. Polymer hydrogels consist of three-dimensional networks of polymer chains cross-linked by physical means. They can be used as micro- or nano-reactors to control the nucleation, assembly, and growth of zeolites [12,13]. By combining TMADaOH and $\mathrm{C}_{22-44} \mathrm{Br}_{2}$ ( 2 bromo-n-22 44 alkane) in the gelation process, a hierarchical pore SSZ-13 molecular sieve was synthesized in one step [14]. However, such methods were usually with a high synthesis cost and low yield, which hindered its further industrial production.

Limited mass transfer in the microporous molecular sieve and formation of coke in the cages could lead to a high deactivation propensity and low efficiency for the catalytic MTO reaction. Introducing hierarchical pores to the zeolite is one of the methods for the extensive utilization of CHA-type zeolite in the MTO reaction [15-17]. At present, extensive studies have also been conducted to reduce the crystal size to the nanoscale or introduce auxiliary mesopores/macropores to obtain hierarchical pore materials [18,19]. The use of organic guide agents, such as a cationic polymer template agent, anionic polyacrylamide (APAM), and/or polydimethyldiallyl chloride (PDADMAC), to self-assemble could result in the formation of hierarchical pores with an intermediate pore size of about 5 20 nm and micropore size of $0.8 \mathrm{~nm}[20,21]$. Such approaches have been proven to be a useful method to prepare mesoporous molecular sieves [22].

The status quo determines that the facile and rapid synthetic method of the SSZ-13 zeolite is crucial to a sustainable methanol economy. This study aimed to demonstrate a novel synthesis process for the SSZ-13 zeolite based on the traditional hydrothermal method. A series of process parameters were optimized, including the quaternary ammonium alkali, silica/alumina ratio, alkali/silicon ratio, water/silicon ratio, amount of seed, aging time, and crystallization temperature. In particular, the role of soft template choline chloride (CC) was revealed. In addition, the effects of CC on the porous characteristics and catalytic performance of SSZ-13 were also examined. It is expected that the synthesis of novel molecular sieve materials will be extended through a greener and more efficient process.

\section{Results and Discussion}

\subsection{The Crystal Structure of Synthesized SSZ-13}

Primarily, a series of processing parameters, including the silica/alumina ratio, alkali/silicon ratio, water/silicon ratio, amount of seed, aging time, and crystallization temperature, were systematically optimized (as shown in Figure S1). The key factor, namely the ratio of $\mathrm{n}(\mathrm{CC}) / \mathrm{n}\left(\mathrm{SiO}_{2}\right)$, impacting the catalyst feature was principally focused. The XRD patterns of synthesized materials with different ratios of $\mathrm{m}(\mathrm{CC}) / \mathrm{m}\left(\mathrm{SiO}_{2}\right)$ are presented in Figure 1. Without the addition of the CC template, the product was an ANA (Analcime)-zeolite in pure phase (Figure 1a). With the addition of the CC template agent, the characteristic peak of ANA at $2 \theta=15.9^{\circ}$ gradually disappeared. The secondary structural unit of SSZ-13 was gradually formed in the mixed gel. As $\mathrm{m}(\mathrm{CC}) / \mathrm{m}\left(\mathrm{SiO}_{2}\right)=0.14$, a pure SSZ-13 phase was generated with a relative crystallinity of $101.2 \%$ (Figure $1 \mathrm{~d}$, Table S1). This could prove that the CC template greatly accelerated the formation of the SSZ-13 structure. In addition, the excessively increasing amount of the CC template agent did not show an apparent influence on the SSZ-13 crystal structure. Therefore, the $\mathrm{m}(\mathrm{CC}) / \mathrm{m}\left(\mathrm{SiO}_{2}\right)$ ratio of 0.14 was the optimal condition to obtain a fully crystallized SSZ-13 molecular sieve with low cost (taking the commercially available SSZ-13 as a reference). 
The optimized condition details for the synthesis of SSZ-13 using the CC template are described in the Supplementary Materials and Figure S1.

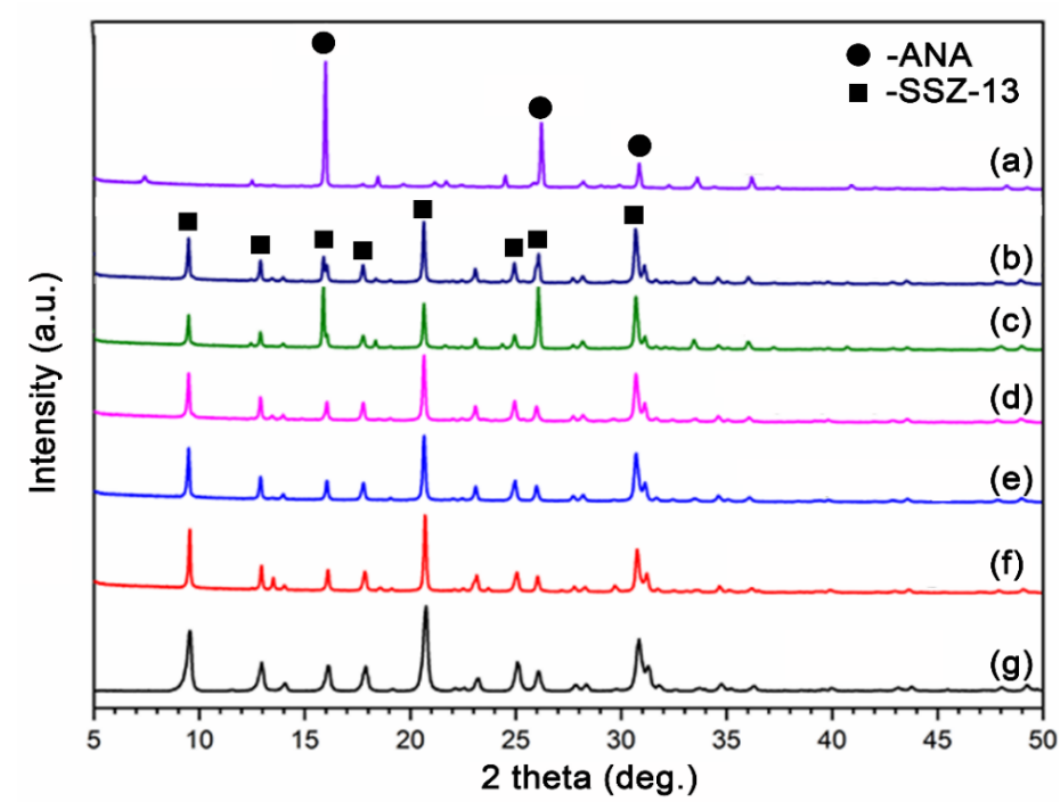

Figure 1. XRD of the SSZ-13 zeolite prepared with different $\mathrm{m}(\mathrm{CC}) / \mathrm{m}\left(\mathrm{SiO}_{2}\right):(\mathbf{a})$, (b) 0.07 , (c) 0.11, (d) $0.14,(\mathbf{e}) 0.21$, (f) 0.32 , and (g) purchased SSZ-13.

\subsection{Morphology of Catalysts}

Figure 2 presents the SEM images of prepared SSZ-13 catalysts with different ratios of $\mathrm{m}(\mathrm{CC}) / \mathrm{m}\left(\mathrm{SiO}_{2}\right)=0.07,0.14$, and 0.32 . The sample prepared by $\mathrm{m}(\mathrm{CC}) / \mathrm{m}\left(\mathrm{SiO}_{2}\right)=0.07$ was irregular particles dominated by a cubic shape and mixed with many differently sized crystals (Figure 2a). It was thought that with the lower addition of the template agent, it would be hard to achieve complete crystallization of the amorphous gel into regular SSZ-13 molecular sieves. The particles were severely aggregated rather than homogeneously dispersive. The serious aggregation was ascribed to the lack of a specification template agent and slow nucleation rate as well as the insufficient crystal nucleus formation during the hydrothermal synthesis. With the $\mathrm{m}(\mathrm{CC}) / \mathrm{m}\left(\mathrm{SiO}_{2}\right)$ ratio increased to 0.14 , the irregular particles gradually disappeared, as shown in Figure 2b. Even though the particles demonstrated slight aggregation, the cubic crystals were homogeneously distributed. The appropriate amount of template could meet the condition for rapid and ordered growth of catalyst crystals. Compared with the synthesized sample with $\mathrm{m}(\mathrm{CC}) / \mathrm{m}\left(\mathrm{SiO}_{2}\right)=0.14$, it could be seen that the purchased commercial SSZ-13 sample was still in serious agglomeration form (Figure 2d). This may indicate the excellent performance of as-prepared SSZ-13 using a choline chloride template. With the $\mathrm{m}(\mathrm{CC}) / \mathrm{m}\left(\mathrm{SiO}_{2}\right)$ ratio increased to 0.32 , the particles became a worse agglomeration (Figure 2c), and the crystal morphology changed to be ambiguous. It was considered that the excessive amount of the choline chloride template might promote the growth of the larger sized crystal and, consequently, induce the locally sudden agglomeration. This is consistent with the XRD analysis that indicated that $\mathrm{m}(\mathrm{CC}) / \mathrm{m}\left(\mathrm{SiO}_{2}\right)=0.14$ is the optimal condition to obtain relative uniform and cubic particles without undesired agglomeration. In addition, the synthesis time was shortened to $4 \mathrm{~h}$, which highly improved the preparing efficiency. 

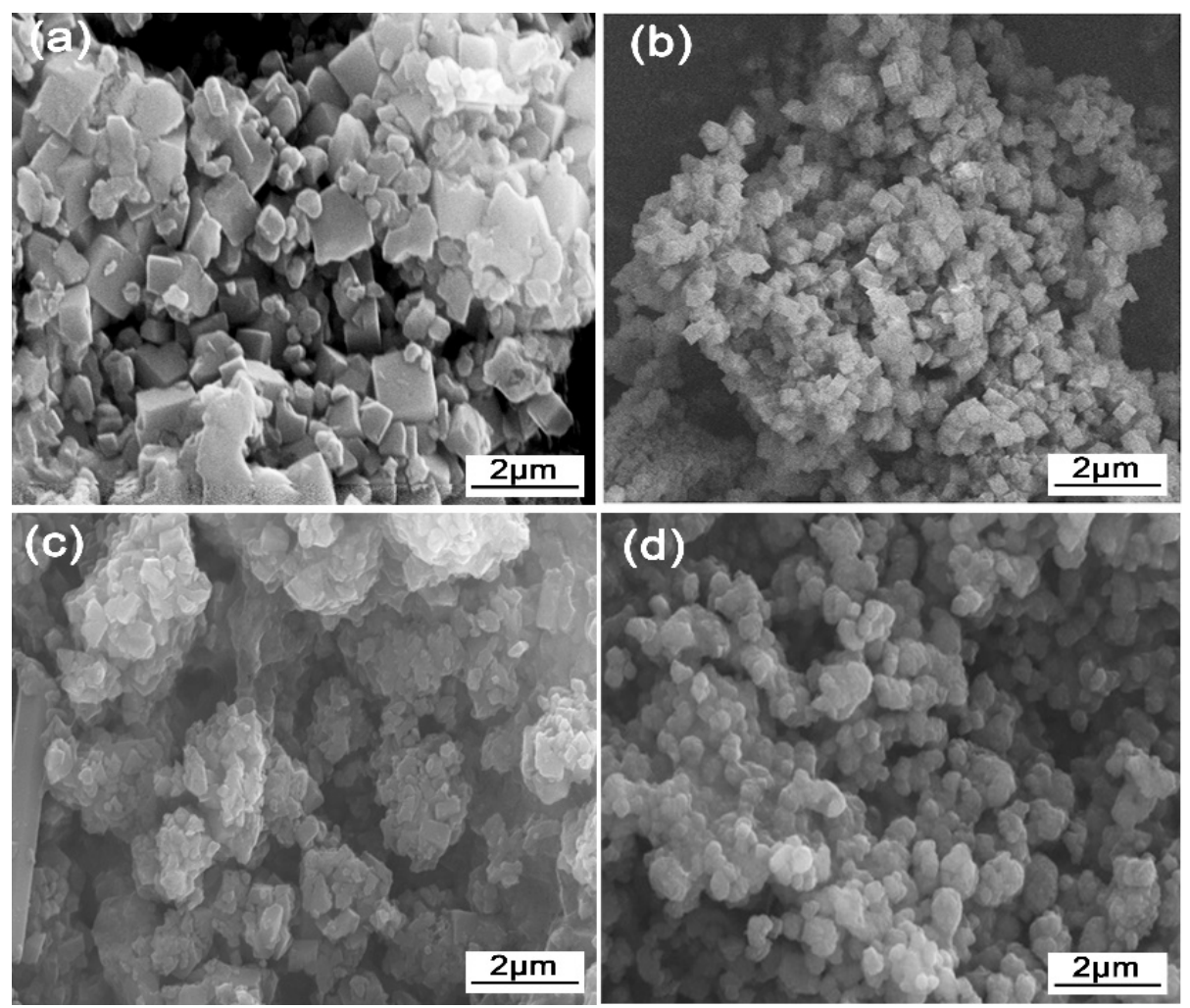

Figure 2. SEM images of SSZ-13 zeolite prepared at different ratios of $\mathrm{m}(\mathrm{CC}) / \mathrm{m}\left(\mathrm{SiO}_{2}\right)$ : (a) 0.07, (b) $0.14,(\mathbf{c}) 0.32$, and (d) purchased SSZ-13.

\subsection{Variation of Microstructure}

The FTIR spectra of the SSZ-13 prepared under different $\mathrm{m}(\mathrm{CC}) / \mathrm{m}\left(\mathrm{SiO}_{2}\right)$ ratios are exhibited in Figure 3. Roughly, the peak vibrations of the synthesized samples were similar. The typical absorption peaks at 460,526, 647, 777, and $1069 \mathrm{~cm}^{-1}$ were assigned to the SSZ-13 molecular sieve. The asymmetric stretching of Si-O-Si or Al-O-Si bond was a wide and strong peak near $1069 \mathrm{~cm}^{-1}$, which was classified as T-O-T vibration. Likewise, the peak at $777 \mathrm{~cm}^{-1}$ was the symmetrical vibration of Al-O. The peak vibration of a single six-member ring was at around $526 \mathrm{~cm}^{-1}$. In addition, ca. $647 \mathrm{~cm}^{-1}$ was the peak vibration of a double six-member ring. The strong absorption peak near $460 \mathrm{~cm}^{-1}$ was due to the bending vibration of Si-O in a silicon-oxygen tetrahedron. The peaks at 1631, 3450, and $3615 \mathrm{~cm}^{-1}$ were the stretching of $-\mathrm{OH}$. Two weak peaks at 2924 and $2849 \mathrm{~cm}^{-1}$ were attributed to the stretching of $-\mathrm{CH}_{2}$ - derived from the residual organic template.

From Figure 3, it can be seen that the absorption peak at $1069 \mathrm{~cm}^{-1}$ became narrower with the $\mathrm{m}(\mathrm{CC}) / \mathrm{m}\left(\mathrm{SiO}_{2}\right)$ ratio increase, indicating the gradual order and regularity of the SSZ-13 crystal. The FTIR is extremely sensitive to the change in the silica-alumina microstructure. With the addition of choline chloride, the absorption peaks at 647 and $526 \mathrm{~cm}^{-1}$ gradually appeared, revealing the formation of a bi-hexagonal ring unit in the SSZ-13 framework. The formation of the bi-hexagonal ring structure proved that the template facilitated the crystallization process; the increase in the absorption peak intensity suggested the crystallization becoming gradually complete. Clearly, the catalyst prepared with $\mathrm{m}(\mathrm{CC}) / \mathrm{m}\left(\mathrm{SiO}_{2}\right)=0.14$ showed the sharpest peak at $1069 \mathrm{~cm}^{-1}$ (Figure 3c), implying the relatively ordered Si-O-Si or Al-O-Si structure without extra distortion. This is consistent with the results discussed in XRD and SEM analyses. 


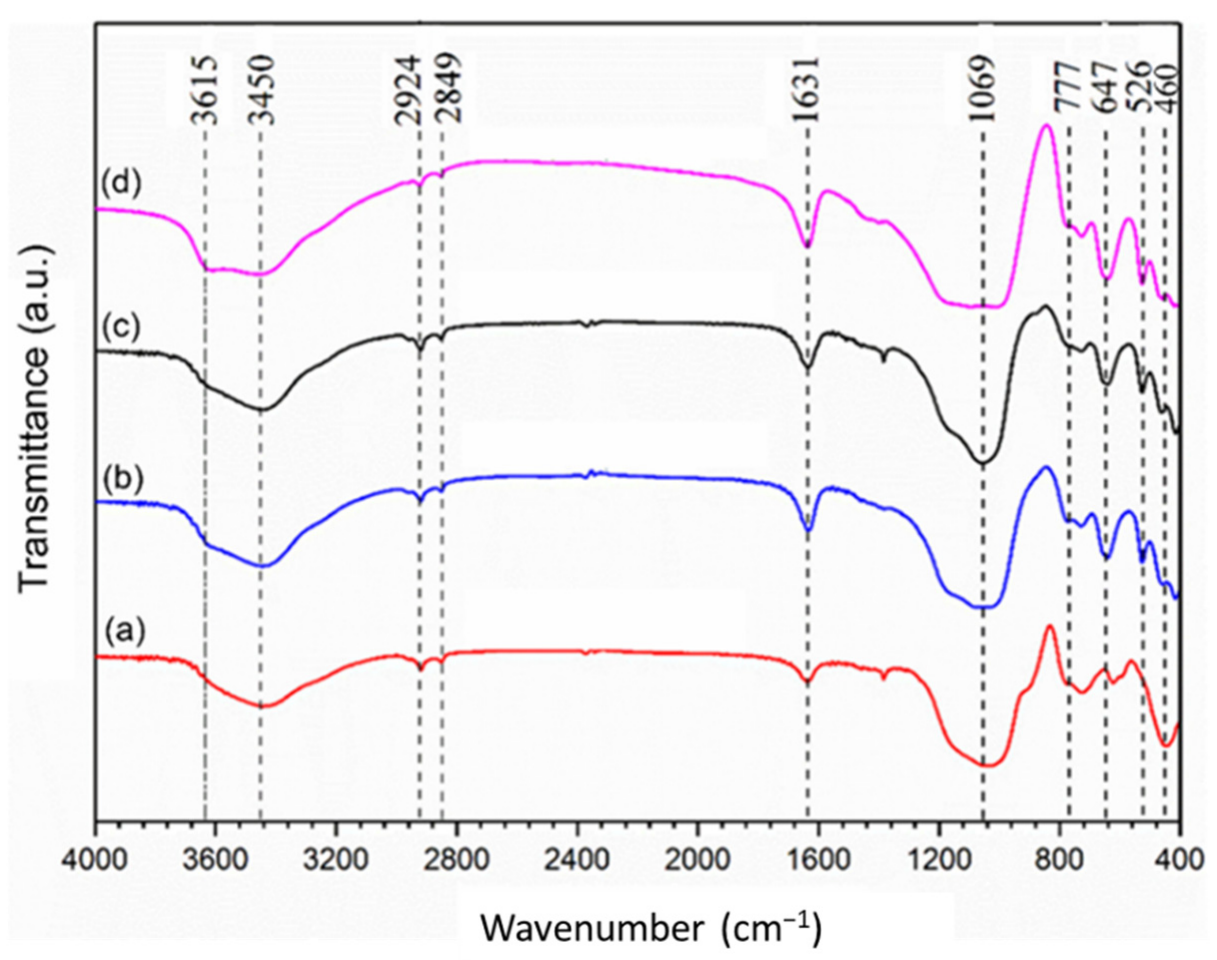

Figure 3. FTIR spectra of synthesized zeolite with different $\mathrm{m}(\mathrm{CC}) / \mathrm{m}\left(\mathrm{SiO}_{2}\right):(\mathbf{a}) 0$, (b) 0.07, (c) 0.14, and (d) 0.32 .

\subsection{The Pore Structure of as-Prepared SSZ-13}

The reactions on the molecular sieve are very sensitive to the framework structure. The adsorption-desorption isotherms of synthesized samples with different $\mathrm{m}(\mathrm{CC}) / \mathrm{m}\left(\mathrm{SiO}_{2}\right)$ are shown in Figure 4. In addition, their surface area and pore volume are listed in Table 1. The results suggest that the synthesized SSZ-13 samples possessed Langmuir adsorption-desorption isothermal curves. The SSZ-13 samples had homogenously distributed microporous channels. In the low-pressure region $\left(10^{-6}<\mathrm{P} / \mathrm{P}_{0}<0.01\right)$, an obvious spike was observed, which was induced by the adsorption of nitrogen molecules in the micropores. The adsorption plateau appeared at $\mathrm{P} / \mathrm{P}_{0}>0.1$, approaching adsorption saturation. At $\mathrm{P} / \mathrm{P}_{0}>0.95$, the adsorption isotherm gradually increased and arrived at the highest point because of capillary condensation. At the relative pressure $\mathrm{P} / \mathrm{P}_{0}=0.45$, the desorption curve closed, forming the hysteretic ring, which indicates that the synthesized zeolite contained stacking mesopores formed by the accumulation of small crystal particles. Such small particles were also found in the SEM images (Figure 2). Particularly, the catalyst prepared with $\mathrm{m}(\mathrm{CC}) / \mathrm{m}\left(\mathrm{SiO}_{2}\right)=0.14$ showed a more significant mesopore structure with an obvious hysteretic ring (Figure $4 \mathrm{~b}$ ). As presented in Table 1, the total specific surface areas of samples prepared at $\mathrm{m}(\mathrm{CC}) / \mathrm{m}\left(\mathrm{SiO}_{2}\right)=0.07,0.14$, and 0.32 were $419.12,641.71$, and $583.62 \mathrm{~m}^{2} \cdot \mathrm{g}^{-1}$, respectively; the mesopore volumes were $0.02,0.04$, and $0.03 \mathrm{~cm}^{3} \cdot \mathrm{g}^{-1}$, respectively. Undoubtedly, the proper amount of template agent with $\mathrm{m}(\mathrm{CC}) / \mathrm{m}\left(\mathrm{SiO}_{2}\right)=0.14$ achieved the largest specific surface area and the highest mesopore volume. 


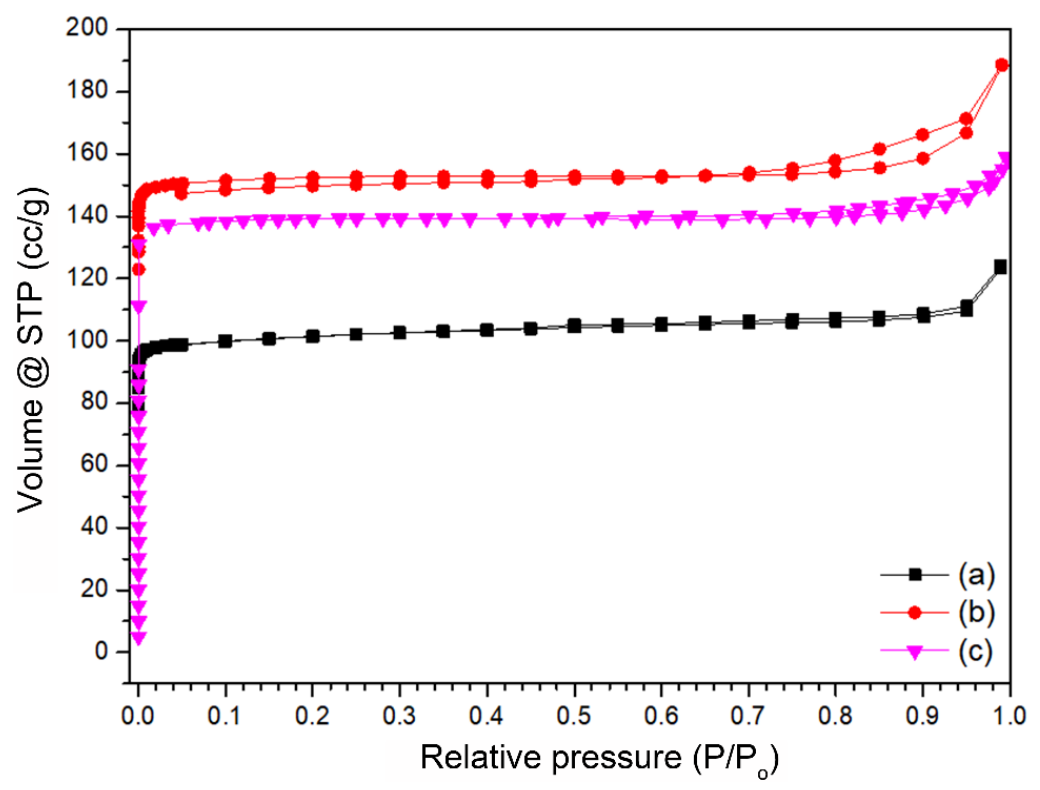

Figure 4. Nitrogen adsorption-desorption isotherms of zeolite prepared with different $\mathrm{m}(\mathrm{CC}) / \mathrm{m}\left(\mathrm{SiO}_{2}\right)$ : (a) 0.07 , (b) 0.14 , and (c) 0.32 .

Table 1. Pore structure characteristics of as-prepared zeolites.

\begin{tabular}{cccccc}
\hline Sample & $\begin{array}{c}\mathbf{S}_{\text {BET }} \\
\left(\mathbf{m}^{\mathbf{2}} \cdot \mathbf{g}^{-\mathbf{1}}\right)\end{array}$ & $\begin{array}{c}\mathbf{S}_{\text {mic }} \\
\left(\mathbf{m}^{\mathbf{2}} \cdot \mathbf{g}^{-\mathbf{1}}\right)\end{array}$ & $\begin{array}{c}\mathbf{S}_{\text {ext }} \\
\left(\mathbf{m}^{\mathbf{2}} \cdot \mathbf{g}^{-\mathbf{1}}\right)\end{array}$ & $\begin{array}{c}\mathbf{V}_{\text {mic }} \\
\left(\mathbf{c m}^{\mathbf{3}} \cdot \mathbf{g}^{\mathbf{1})}\right.\end{array}$ & $\begin{array}{c}\mathbf{V}_{\text {meso }} \\
\left(\mathbf{c m}^{\mathbf{3}} \cdot \mathbf{g}^{-\mathbf{1})}\right.\end{array}$ \\
\hline $\mathrm{m}(\mathrm{CC}) / \mathrm{m}\left(\mathrm{SiO}_{2}\right)=0.07$ & 419.18 & 410.64 & 8.54 & 0.16 & 0.02 \\
$\mathrm{~m}(\mathrm{CC}) / \mathrm{m}\left(\mathrm{SiO}_{2}\right)=0.14$ & 641.71 & 636.06 & 5.65 & 0.24 & 0.04 \\
$\mathrm{~m}(\mathrm{CC}) / \mathrm{m}\left(\mathrm{SiO}_{2}\right)=0.32$ & 583.62 & 569.04 & 14.57 & 0.21 & 0.03 \\
\hline
\end{tabular}

\subsection{The Acidity of SSZ-13}

The ammonia temperature-programmed desorption method $\left(\mathrm{NH}_{3}-\mathrm{TPD}\right)$ could reveal the acid properties of the as-prepared SSZ-13. The $\mathrm{NH}_{3}$-TPD of the SSZ-13 catalysts prepared with different $\mathrm{m}(\mathrm{CC}) / \mathrm{m}\left(\mathrm{SiO}_{2}\right)$ and purchased SSZ-13 are presented in Figure 5. There were two typical desorption peaks found in the samples. The peak near $200{ }^{\circ} \mathrm{C}$ was the low-temperature desorption region, which was attributed to the interaction between acid level and ammonia gas. $\mathrm{NH}_{3}$ could be desorbed from these weakly acidic surface hydroxyl groups, forming the weak acid potential of SSZ-13. The peak in the range of $490 \sim 540{ }^{\circ} \mathrm{C}$ was the high-temperature desorption peak from the bridging hydroxyl group ( $\equiv \mathrm{Si}-\mathrm{OH}-\mathrm{Al} \equiv$ ), corresponding to the strong acid center. The desorption peaks in the low-temperature region were stronger, suggesting that the weak acid sites were dominant. With the increase in $\mathrm{m}(\mathrm{CC}) / \mathrm{m}\left(\mathrm{SiO}_{2}\right)$, the strong acid potential tended to shift to a high-temperature region. The corresponding peak area increased greatly at $\mathrm{m}(\mathrm{CC}) / \mathrm{m}\left(\mathrm{SiO}_{2}\right)=0.14$. Table 2 shows that the weak and strong acidities of $\mathrm{m}(\mathrm{CC}) / \mathrm{m}\left(\mathrm{SiO}_{2}\right)=0.14$ were 0.67 and $0.55 \mathrm{mmol} / \mathrm{g}$, respectively. According to the SEM images, at $\mathrm{m}(\mathrm{CC}) / \mathrm{m}\left(\mathrm{SiO}_{2}\right)=0.14$, the particle size distribution became more uniform and the specific surface area increased significantly, indicating a larger amount of acid sites on the surface. The optimized strong and weak acid sites were obtained by regulating the $\mathrm{m}(\mathrm{CC}) / \mathrm{m}\left(\mathrm{SiO}_{2}\right)$, which would be conducive to the catalytic performance of such a catalyst under relatively low temperature. 


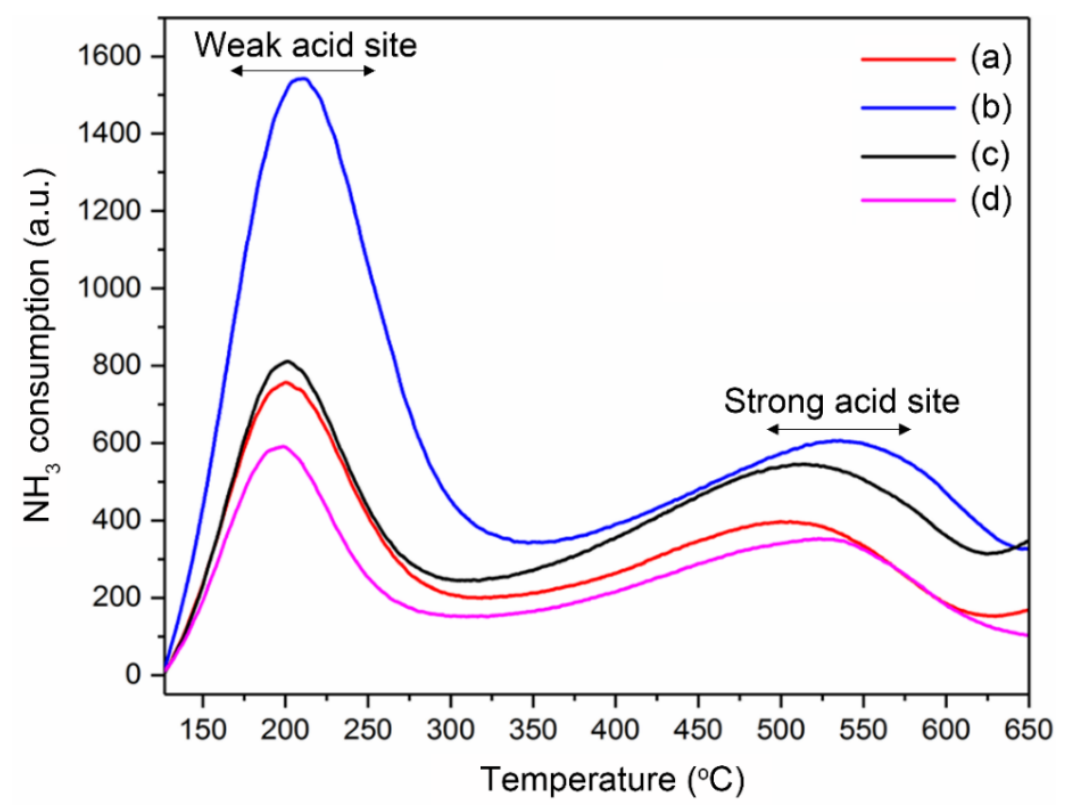

Figure 5. $\mathrm{NH}_{3}$-TPD of samples with different $\mathrm{m}(\mathrm{CC}) / \mathrm{m}\left(\mathrm{SiO}_{2}\right):$ (a) 0.07 , (b) 0.14, (c) 0.32, and (d) purchased SSZ-13.

Table 2. The acidity of as-prepared SSZ-13 measured by $\mathrm{NH}_{3}$-TPD.

\begin{tabular}{ccccc}
\hline \multirow{2}{*}{ Samples } & \multicolumn{2}{c}{ Weak Acid Site } & \multicolumn{2}{c}{ Strong Acid Site } \\
\cline { 2 - 5 } & $\begin{array}{c}\text { Temperature } \\
\left({ }^{\circ} \mathbf{C}\right)\end{array}$ & $\begin{array}{c}\text { Acidity } \\
(\mathbf{m m o l} / \mathbf{g})\end{array}$ & $\begin{array}{c}\text { Temperature } \\
\left({ }^{\circ} \mathbf{C}\right)\end{array}$ & $\begin{array}{c}\text { Acidity } \\
(\mathbf{m m o l} / \mathbf{g})\end{array}$ \\
\hline $\mathrm{m}(\mathrm{CC}) / \mathrm{m}\left(\mathrm{SiO}_{2}\right)=0.07$ & 200 & 0.43 & 505 & 0.51 \\
$\mathrm{~m}(\mathrm{CC}) / \mathrm{m}\left(\mathrm{SiO}_{2}\right)=0.14$ & 210 & 0.67 & 536 & 0.55 \\
$\mathrm{~m}(\mathrm{CC}) / \mathrm{m}\left(\mathrm{SiO}_{2}\right)=0.32$ & 201 & 0.45 & 511 & 0.80 \\
Purchased SSZ-13 & 203 & 0.35 & 510 & 0.56 \\
\hline
\end{tabular}

\subsection{Catalytic Performance for MTO Reaction}

Based on the optimal conditions described, the catalytic activity of the synthesized SSZ-13 material for the MTO reaction was evaluated. As a typical acid catalytic reaction, SSZ-13 can demonstrate the role of a bifunctional catalyst. The catalytic performance of purchased (using the TMAdaOH as template) and synthesized (using the CC as template with $\mathrm{m}(\mathrm{CC}) / \mathrm{m}(\mathrm{SiO} 2)=0.14) \mathrm{SSZ}-13$ for the MTO reaction is shown in Figures 6 and 7. The products were mainly C1 C3 alkanes and alkenes. The ethylene and propylene were the dominant compounds, and their yield reached its highest at 60 90 min. The yields were maintained at over $35 \%$ during the test. The main byproducts were $\mathrm{CH}_{4}, \mathrm{C}_{2} \mathrm{H}_{6}$, and $\mathrm{C}_{3} \mathrm{H}_{8}$. In the early stage (before $40 \mathrm{~min}$ ) of the MTO reaction, the methanol was first decarbonylated for the formation of intermediates, such as acetate, formate, methyl acetate, and dimethoxymethane, while the zeolite was carbonylated during the induction period. The yield of byproducts was continuously decreased during the reaction period, indicating the improvement of reaction selectivity and deactivation of the catalyst. 


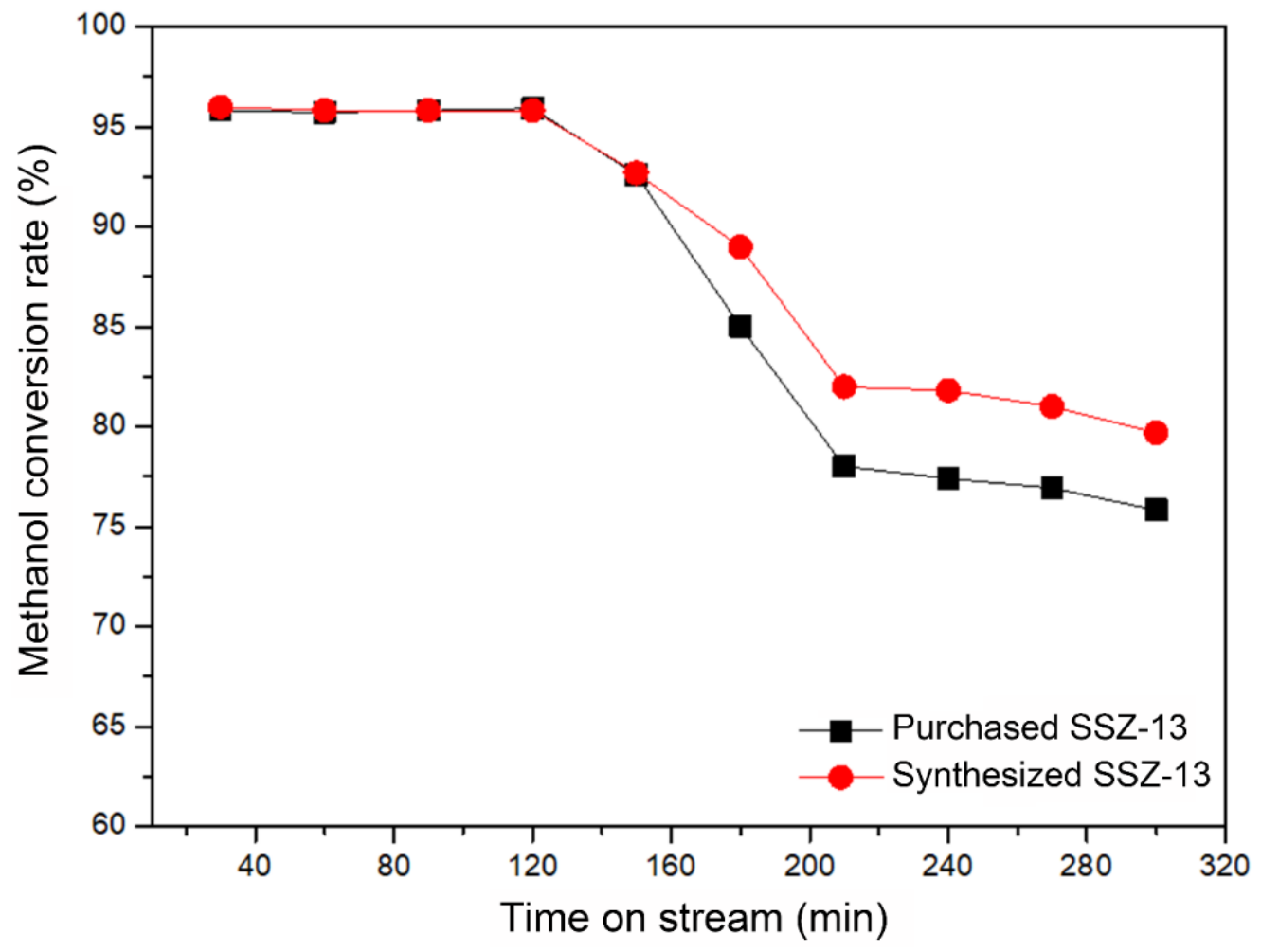

Figure 6. The methanol conversion rate of purchased and synthesized SSZ-13 catalysts.

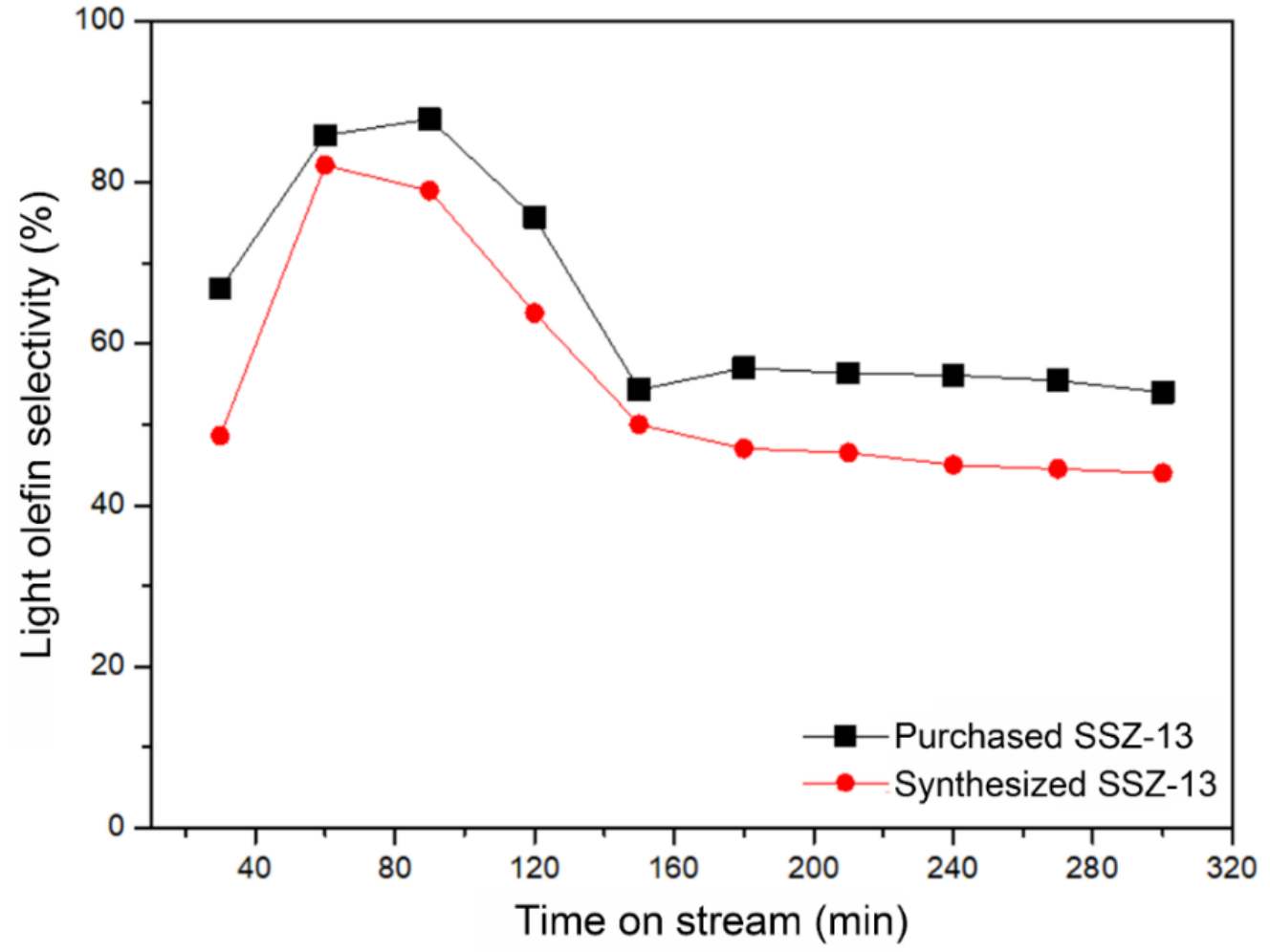

Figure 7. The low olefin selectivity of purchased and synthesized SSZ-13 catalysts.

Both the SSZ-13 catalysts maintained a high methanol conversion rate over $95 \%$ within a reaction time of $120 \mathrm{~min}$, and it drastically dropped to ca. $80 \%$ at $80 \mathrm{~min}$. Eventually, the conversion rate was maintained at ca. $75 \%$ in a long reaction period (Figure 6 ). The synthesized SSZ-13 exhibited a better conversion rate than that of the purchased one. The 
catalytic lifetime of the molecular sieve was defined as the duration that the methanol conversion was kept above $90 \%$, i.e., the time from the beginning of the reaction to the methanol conversion dropping to $90 \%$. From the $\mathrm{NH}_{3}$-TPD analyses, the weak acidity of synthesized $(\mathrm{m}(\mathrm{CC}) / \mathrm{m}(\mathrm{SiO} 2)=0.14)$ and purchased SSZ-13 was 0.67 and $0.35 \mathrm{mmol} / \mathrm{g}$, respectively; the strong acidity was 0.55 and $0.56 \mathrm{mmol} / \mathrm{g}$, respectively. Consequently, the as-prepared and purchased samples exhibited obvious differences in the catalytic lifetime. Their catalyst lifetimes were 172 and $160 \mathrm{~min}$, respectively. The reaction intermediates, such as methylbenzene, were gradually converted into polycyclic aromatic hydrocarbons, which might have caused accumulation on the internal surface and outside the cage of SSZ-13, thus leading to congestion of the channel and a lower mass transfer rate. Eventually, it became difficult for the reactants to contact the active center, resulting in catalyst deactivation. It was considered that the appropriate acidity and well-developed pore structure of synthesized SSZ-13 could slow down the carbon deposition rate and significantly increase the lifetime of the catalyst.

Both SSZ-13 catalysts showed an induction period where the selectivity was quite low during the initial $40 \mathrm{~min}$, as shown in Figure 7. The light olefin selectivity was highest at the reaction time of ca. $60 \mathrm{~min}$. The methanol adsorbed at the acid site was the first step of MTO conversion; the deprotonation of carbenium ions and shift of methyl groups were the following reaction. The framework structure of SSZ-13 accelerated the deprotonation of carbenium ions and converted the methyl group into the alkene [23]. Such an induction reaction could occur under a low reaction temperature (i.e., $<450{ }^{\circ} \mathrm{C}$ ). The active hydrocarbon species formed inside the zeolite at the initial stage. Theoretically, the synthesized SSZ-13 with higher acidity would possess a strong adsorption capacity. The light olefine selectivity of the as-prepared SSZ-13 was slightly lower than that of the purchased SSZ-13. It was thus thought that the excessive micropore hindered the timely desorption and diffusion of intermediate products and consequently reduced the light olefin selectivity. Although the light olefin selectivity of the synthesized SSZ-13 was slightly lower than that of the purchased SSZ-13, the initial selectivity could be maintained above $50 \%$ within $160 \mathrm{~min}$ with the conversion rate over $90 \%$. The larger amount of weak acid sites and relative smaller amount of strong acid sites on the as-prepared SSZ-13 using choline chloride as a template were beneficial for the low temperature catalytic performance and longer lifetime.

\section{Experimental Section}

\subsection{Materials}

Sodium hydroxide $(\mathrm{NaOH})$, sodium meta-aluminate $\left(\mathrm{NaAlO}_{2}\right)$, aluminum isopropoxide $\left(\mathrm{C}_{9} \mathrm{H}_{21} \mathrm{AlO}_{3}\right)$, silica-sol LUDOX-40 $\left(\mathrm{mSiO}_{2} \cdot \mathrm{nH}_{2} \mathrm{O}\right)$, aluminum nitrate nonahydrate $\left(\mathrm{Al}\left(\mathrm{NO}_{3}\right)_{3} \cdot 9 \mathrm{H}_{2} \mathrm{O}\right)$, ammonium chloride $\left(\mathrm{NH}_{4} \mathrm{Cl}\right)$, and choline chloride $\left(\mathrm{C}_{5} \mathrm{H}_{14} \mathrm{ClNO}\right)$ were purchased from Shanghai MackLin Biochemical Technology Co., Ltd. (Shanghai, China). The reagents used in this study were analytical pure (AR).

\subsection{Sample Preparation}

The catalysts were prepared using the hydrothermal synthesis method. In the synthesis process, the ratios of precursors were $\mathrm{n}\left(\mathrm{SiO}_{2}\right) / \mathrm{n}\left(\mathrm{Al}_{2} \mathrm{O}_{3}\right)=40, \mathrm{n}\left(\mathrm{Na}_{2} \mathrm{O}\right) / \mathrm{n}\left(\mathrm{SiO}_{2}\right)=0.4$, and $\mathrm{n}\left(\mathrm{H}_{2} \mathrm{O}\right) / \mathrm{n}\left(\mathrm{SiO}_{2}\right)=12$. The ratio of $\mathrm{m}(\mathrm{CC}) / \mathrm{m}\left(\mathrm{SiO}_{2}\right)$ was varied from 0 to 0.32 . The SSZ13 crystal seed was added into the solution with a ratio of $\mathrm{m}(\mathrm{seed}) / \mathrm{m}\left(\mathrm{SiO}_{2}\right)=0.4 \%$. During the synthesis process, ca. $3.60 \mathrm{~g} \mathrm{NaOH}$ and $0.49 \mathrm{~g} \mathrm{NaAlO}_{2}$ were dissolved in deionized water, which was subsequently added in a $2.30 \mathrm{~g}$ CC template agent. This solution was stirred for $10 \mathrm{~min}$ to ensure sufficient mixing. Subsequently, a commercially available SSZ-13 (Aos Catalytic Materials (Dalian, China) Co., Ltd.) was introduced as a homogenous seed. After intense stirring at room temperature for $20 \mathrm{~min}, 18.00 \mathrm{~g}$ of inorganic silica sol (Ludox-40) was added to the solution slowly. Upon stirring for another $30 \mathrm{~min}$, the initial gel was transferred to a purchased hydrothermal reaction kettle lined with polytetrafluoroethylene, which was placed in a blast-drying oven at a constant temperature of $120^{\circ} \mathrm{C}$ and static 
crystallization. After a period of crystallization, the products were washed to neutral and then dried at $120^{\circ} \mathrm{C}$. Finally, the solid product was placed in a muffle furnace and calcined at $550{ }^{\circ} \mathrm{C}$. The templating agent was thus removed to obtain the Na-type SSZ-13 molecular sieve. The $\mathrm{NH}_{4}$-SSZ-13 molecular sieve was obtained by exchanging the Na-type SSZ-13 with $1 \mathrm{~mol} / \mathrm{L}$ of $\mathrm{NH}_{4} \mathrm{Cl}$ solution 3 times, and, sequentially, the H-type SSZ-13 was prepared after drying and calcination.

\subsection{Characterization of Zeolites}

X-ray diffraction (XRD) analysis was conducted on a Rigaku RINT ultimate-III powder diffractometer (Rigaku Co., Ltd., Osaka, Japan). The sample was in powder form. The $2 \theta$ range was $5 \sim 50^{\circ}$ with a scanning rate of $10^{\circ} / \mathrm{min}$. Cu target $K_{\beta}$ radiation was used with a tube voltage of $40 \mathrm{kV}$ and a tube current of $30 \mathrm{~mA}$. A scanning electron microscope (SEM, H-7650 Hitachi Co., Ltd., Tokyo, Japan) was used to characterize the morphology and particle size of the materials prepared. FTIR analyses of the raw and as-prepared materials were conducted using an FT/IR-615 JASCO (JASCO, Ltd., Tokyo, Japan) spectrometer in transmission mode. First, the sample (ca. $1 \mathrm{mg}$ ) was ground to powder with a size of about 200 mesh and mixed with $\mathrm{KBr}$ (ca. $500 \mathrm{mg}$ ) using the normal $\mathrm{KBr}$ procedure to make the pellet. Then, the pellets were dried in an oven at $60{ }^{\circ} \mathrm{C}$ for $12 \mathrm{~h}$. During analysis, the resolution was $4 \mathrm{~cm}^{-1}$ in the range of $4000 \sim 400 \mathrm{~cm}^{-1}$ wave number, and perspectrum was 32 scans. Nitrogen absorption and desorption tests were performed using an Autosorb iQ Station 1 (Quantachrome, Florida, United States). Pore volume and size distribution were calculated with the DFT model. Before measurement, the samples were pretreated in vacuum at $200{ }^{\circ} \mathrm{C}$ for $12 \mathrm{~h}$. The surface acidity of as-prepared zeolite was determined by ammonia temperature-programmed desorption $\left(\mathrm{NH}_{3}-\mathrm{TPD}\right)$. Chemical adsorption apparatus (BELCATII Co., Ltd., Tokyo, Japan) equipped with a thermal conductivity detector was used. About $0.05 \mathrm{~g}$ of the molecular sieve was loaded into the U-type tube reactor, and then $0.04 \mathrm{~g}$ ultrafine silica wool was added to prevent the gas from drifting away. The adsorbed gas was then removed from the sample by heating in an inert gas atmosphere to $350{ }^{\circ} \mathrm{C}$. Subsequently, the sample was cooled to $100{ }^{\circ} \mathrm{C}$ under an ammonia flow (flow rate $30 \mathrm{sccm}$, time $60 \mathrm{~min}$ ) to achieve saturated adsorption. The He (30 $\mathrm{mL} / \mathrm{min}$ ) was injected for about $30 \mathrm{~min}$ to remove the physically adsorbed ammonia gas. Finally, TPD was heated to $700{ }^{\circ} \mathrm{C}$ in $\mathrm{He}$ with a heating rate of $10^{\circ} \mathrm{C} / \mathrm{min}$, and the amount of ammonia gas de-adsorbed from the acidic center was measured by a thermal conductivity cell detector.

\subsection{Evaluation of the Catalytic Performance}

The MTO reaction was carried out in a fixed-bed quartz tube reactor $(\Phi 6 \mathrm{~mm})$ using the as-prepared catalysts. The schematic of the fixed-bed reactor is illustrated in Figure 8. About $300 \mathrm{mg}$ molecular sieve catalyst (40 60 mesh) and $2.7 \mathrm{~g}$ quartz sand were well mixed and loaded into the reactor. The reactor was then heated to $550{ }^{\circ} \mathrm{C}$ with an interval of $10{ }^{\circ} \mathrm{C} / \mathrm{min}$ to first remove the impurities adsorbed in a molecular sieve for $1 \mathrm{~h}$. Subsequently, the temperature was set to a reaction temperature of $450{ }^{\circ} \mathrm{C}$ for $20 \mathrm{~min}$. The weight hourly space velocity (WHSV) was $3 \mathrm{~h}^{-1}$. The reaction products were identified and quantified through an in situ gas chromatograph (GC). 


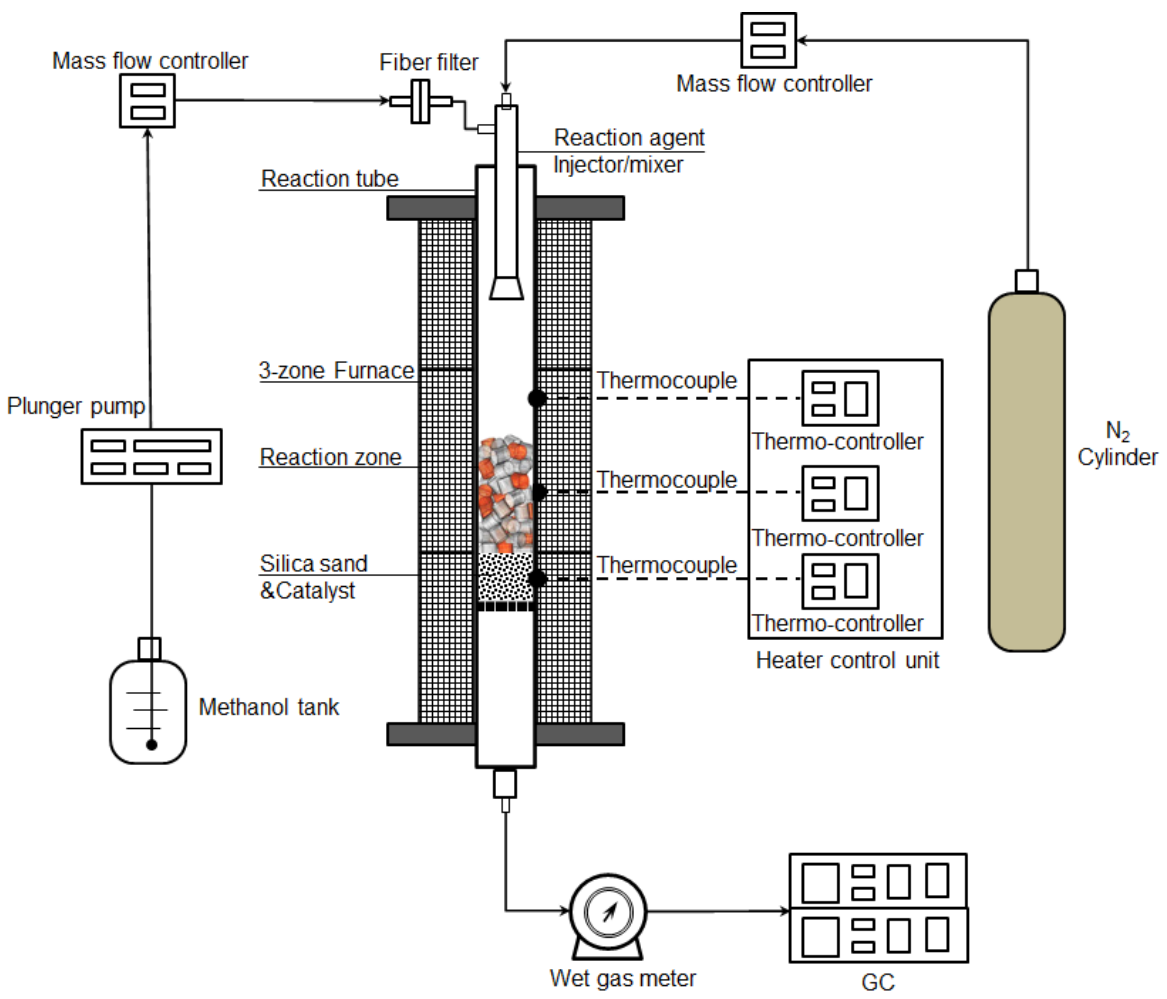

Figure 8. Schematic of the fixed-bed reactor.

\section{Conclusions}

The time consumption, high cost, and polluting synthesis process are the key drawbacks for the industrial utilization of SSZ-13 catalysts in MTO technology. This work demonstrated a facile and rapid synthesis approach for SSZ-13 using choline chloride as a template. The optimal synthesis condition was explored, and the catalytic performance for the methanol-to-olefins (MTO) reaction was examined. The choline chloride was proved to be effective for the synthesis of SSZ-13. An appropriate ratio of the soft template could meet the condition for rapid and ordered growth of catalyst crystals. The special molecular structure of choline chloride could greatly accelerate the formation of bi-hexagonal ring structure in the SSZ-13 framework, and it could shorten the synthesis cycle to within $4 \mathrm{~h}$. With a proper amount of choline chloride addition (i.e., $\mathrm{m}(\mathrm{CC}) / \mathrm{m}\left(\mathrm{SiO}_{2}\right)=0.14$ ), uniform and homogeneously distributed cubic SSZ-13 crystals were obtained with lower aggregation. The catalyst synthesized with $\mathrm{m}(\mathrm{CC}) / \mathrm{m}\left(\mathrm{SiO}_{2}\right)=0.14$ demonstrated excellent porous features with a total specific surface area and mesopore volume of $641.71 \mathrm{~m}^{2} \cdot \mathrm{g}^{-1}$ and $0.04 \mathrm{~cm}^{3} \cdot \mathrm{g}^{-1}$, respectively. The optimized strong and weak acid sites on SSZ-13 were obtained by regulating the $\mathrm{m}(\mathrm{CC}) / \mathrm{m}\left(\mathrm{SiO}_{2}\right)$. As a typical acid catalytic reaction, the SSZ-13 catalyst with strong and weak acid sites exhibited a bifunctional role. The lower amount of strong acid sites and a larger amount of weak acid sites in the synthesized catalyst were conducive to the catalytic performance for the MTO reaction under a relatively lower reaction temperature. The methanol conversion rate using synthesized catalyst was maintained over $95 \%$ within $120 \mathrm{~min}$, and its lifetime was achieved to $172 \mathrm{~min}$. The appropriate acidity and well-developed pore structure of synthesized SSZ-13 could slow down the carbon deposition rate and significantly increase the lifetime of the catalyst. Moreover, the initial selectivity of light olefin could be maintained above $50 \%$ within $160 \mathrm{~min}$. Although the low olefin selectivity of the synthesized SSZ-13 catalyst was slightly lower than that of purchased one, its desirable features were thought to have good potential for industrial application. 
Supplementary Materials: The following are available online at https://www.mdpi.com/article/10 .3390 / catal11101250/s1, Figure S1: The XRD information of the product with changes in different conditions: (a) quaternary ammonium bases; (b) ratio of $\mathrm{n}\left(\mathrm{SiO}_{2}\right) / \mathrm{n}\left(\mathrm{Al}_{2} \mathrm{O}_{3}\right),(\mathrm{c}) \mathrm{n}\left(\mathrm{Na}_{2} \mathrm{O}\right) / \mathrm{n}\left(\mathrm{SiO}_{2}\right)$, and $(\mathrm{d}) \mathrm{n}\left(\mathrm{H}_{2} \mathrm{O}\right) / \mathrm{n}\left(\mathrm{SiO}_{2}\right)$, Figure S2: The XRD information of the product with changes in different conditions: (a) inoculating seed, (b) aging, (c) crystallization temperature (Tcrystal.), (d) crystallization time (tcrystal.), Figure S3: XRD of SSZ-13 synthesized under optimal conditions, Figure S4: XRD of products in different TPPS amounts, Figure S5: XRD of products in different KH550 amounts, Figure S6: XRD of products in different PAAS amounts, Table S1: The phase of synthetic products in different $\mathrm{n}\left(\mathrm{H}_{2} \mathrm{O}\right) / \mathrm{n}\left(\mathrm{SiO}_{2}\right)$, Table S2: The phase of synthetic products at different aging times, Table S3: The phase of synthetic products at different crystallization times, Table S4: The phase of synthetic products in different $\mathrm{m}(\mathrm{CC}) / \mathrm{m}\left(\mathrm{SiO}_{2}\right)$, Table S5: Different mass ratio of TPPS and Ludox-40, Table S5: Mass ratio of KH550 to Ludox-40, Table S6: FWHM data of (101) crystal plane of samples after crystallization for 2 days.

Author Contributions: Writing-review and editing, funding acquisition: X.L. (Xiongchao Lin); writing - original draft preparation, methodology: S.Y.; methodology, formal analysis: X.L. (Xiaojia Li); formal analysis: C.W.; formal analysis: Y.W. All authors have read and agreed to the published version of the manuscript.

Funding: This work was supported by the National Natural Science Foundation of China (grant numbers 21978319, 22008253, 21406261), the National Key Research and Development Program (Grant number 2016YFB0600303031), and the Yueqi Outstanding Scholar Project (Project Number 2020JCB02).

Data Availability Statement: Data is contained within the article.

Acknowledgments: We are grateful to our Department of Instrumental Analysis for the analysis of SEM.

Conflicts of Interest: The authors declare no conflict of interest.

\section{References}

1. Zhou, Y.; Qi, L.; Wei, Y.; Yuan, C.; Zhang, M.; Liu, Z. Methanol-to-olefin induction reaction over SAPO-34. Chin. J. Catal. 2016, 37, 1496-1501. [CrossRef]

2. Deimund, M.A.; Harrison, L.; Lunn, J.D.; Liu, Y.; Malek, A.; Shayib, R.; Davis, M.E. Effect of heteroatom concentration in SSZ-13 on the methanol-to-olefins reaction. ACS Catal. 2016, 6, 542-550. [CrossRef]

3. Standl, S.; Hinrichsen, O. Kinetic modeling of catalytic olefin cracking and methanol-to-olefins (MTO) over zeolites: A review. Catalysts 2018, 12, 626. [CrossRef]

4. Tian, P.; Wei, Y.; Ye, M.; Liu, Z. Methanol to olefins (MTO): From fundamentals to commercialization. ACS Catal. 2015, 5, 1922-1938. [CrossRef]

5. Han, L.; Jiang, X.G.; Lu, T.L.; Wang, B.S.; Xu, J.; Zhan, Y.Z.; Zhao, C. Preparation of composite zeolites in polymer hydrogels and their catalytic performances in the methanol-to-olefin reaction. Fuel Process. Technol. 2017, 165, 87-93. [CrossRef]

6. Ferri, P.; Li, C.; Millán, R.; Martínez-Triguero, J.; Moliner, M.; Boronat, M.; Corma, A. Impact of Zeolite Framework Composition and Flexibility on Methanol-To-Olefins Selectivity: Confinement or Diffusion? Angew. Chem. Int. Ed. 2020, 132, 1-9. [CrossRef]

7. Liu, B.; Zhou, R.; Bu, N.; Wang, Q.; Zhong, S.; Wang, B.; Hidetoshi, K. Room-temperature ionic liquids modified zeolite SSZ-13 membranes for $\mathrm{CO}_{2} / \mathrm{CH}_{4}$ separation. J. Membr. Sci. 2017, 524, 12-19. [CrossRef]

8. Jun, J.W.; Khan, N.A.; Seo, P.W.; Kim, C.U.; Kim, H.J.; Jhung, S.H. Conversion of Y into SSZ-13 zeolites and ethylene-to-propylene reactions over the obtained SSZ-13 zeolites. Chem. Eng. J. 2016, 303, 667-674. [CrossRef]

9. Zeng, L.; Yu, Z.; Sun, Z.; Han, Y.; Xu, Y.; Wu, J.; Wang, Z. Fast synthesis of SSZ-13 zeolite by steam-assisted crystallization method. Microporous Mesoporous Mater. 2020, 293, 109789. [CrossRef]

10. Wang, J.; Peng, Z.; Chen, Y.; Bao, W.; Chang, L.; Feng, G. In-Situ hydrothermal synthesis of Cu-SSZ-13/cordierite for the catalytic removal of $\mathrm{NO}_{x}$ from diesel vehicles by $\mathrm{NH}_{3}$. Chem. Eng. J. 2015, 263, 9-19. [CrossRef]

11. Sommer, L.; Mores, D.; Svelle, S.; Stöcker, M.; Weckhuysen, B.M.; Olsbye, U. Mesopore formation in zeolite H-SSZ-13 by desilication with $\mathrm{NaOH}$. Microporous Mesoporous Mater. 2010, 132, 384-394. [CrossRef]

12. Li, Z.; Navarro, M.T.; Martínez-Triguero, J. Synthesis of nano-SSZ-13 and its application in the reaction of methanol to olefins. Catal. Sci. Technol. 2016, 6, 5856-5863. [CrossRef]

13. Zhu, X.; Hofmann, J.P.; Mezari, B. Trimodal Porous Hierarchical SSZ-13 Zeolite with Improved Catalytic Performance in the Methanol-to-Olefins Reaction. ACS Catal. 2016, 6, 2163-2177. [CrossRef]

14. Zhang, X.Y.; Dou, T.T.; Yao, W.; Yang, J.Y.; Wang, X.; Guo, Y.Y.; Shen, Q.; Zhang, X.; Zhang, S.Q. Green synthesis of Cu-SSZ-13 zeolite by seed-assisted route for effective reduction of nitric oxide. J. Clean Prod. 2019, 117667. [CrossRef] 
15. Xu, R.; Zhang, R.; Liu, N.; Chen, B.; Zhang, S. Template Design and Economical Strategy for the Synthesis of SSZ-13 (CHA-Type) Zeolite as an Excellent Catalyst for the Selective Catalytic Reduction of $\mathrm{NO}_{\mathrm{x}}$ by Ammonia. ChemCatChem 2015, 7, 3842-3847. [CrossRef]

16. Zhu, X.; Rohling, R.; Filonenko, G.; Mezari, B.; Hofmann, J.P.; Asahina, S.; Hensen, E.J. Synthesis of hierarchical zeolites using an inexpensive mono-quaternary ammonium surfactant as mesoporogen. Chem. Commun. 2014, 50, 14658-14661. [CrossRef] [PubMed]

17. Tang, T.; Yin, C.; Wang, L. Good sulfur tolerance of a mesoporous Beta zeolite-supported palladium catalyst in the deep hydrogenation of aromatics. J. Catal. 2008, 257, 125-133. [CrossRef]

18. Wu, L.; Hensen, E.J. Comparison of mesoporous SSZ-13 and SAPO-34 zeolite catalysts for the methanol-to-olefins reaction. Catal. Today 2014, 235, 160-168. [CrossRef]

19. Li, X.; Shen, W.; Zheng, A. The influence of acid strength and pore size effect on propene elimination reaction over zeolites: A theoretical study. Microporous Mesoporous Mater. 2019, 278, 121-129. [CrossRef]

20. Janssen, A.H.; Schmidt, I.; Jacobsen, C.J.H.; Koster, A.J.; Jong, K.P.D. Exploratory study of mesopore templating with carbon during zeolite synthesis. Microporous Mesoporous Mater. 2003, 65, 59-75. [CrossRef]

21. Xiao, F.S.; Wang, L.; Yin, C. Catalytic properties of hierarchical mesoporous zeolites templated with a mixture of small organic ammonium salts and mesoscale cationic polymers. Angew. Chem. Int. Ed. 2006, 45, 3090-3093. [CrossRef] [PubMed]

22. Wardani, M.; Kadja, G.; Fajar, A.; Makertihartha, I.; Gunawan, M.; Suendo, V.; Mukti, R. Highly crystalline mesoporous SSZ-13 zeolite obtained via controlled post-synthetic treatment. RSC Adv. 2019, 9, 77-86. [CrossRef]

23. Li, D.; Xing, B.; Wang, B.; Li, R. Activity and selectivity of methanol-to-olefin conversion over Zr-modified H-SAPO-34/H-ZSM-5 zeolites-A theoretical study. Fuel Process. Technol. 2020, 199, 106302. [CrossRef] 